\title{
Uso de resíduo da fabricação da farinha de mandioca para produção otimizada de biodiesel
}

Durante a fabricação da farinha de mandioca após o processo de prensagem ocorre a extração de um líquido rico em ácido cianídrico, venenoso para a nutrição animal, conhecido popularmente como manipueira. A manipueira é a água residuária proveniente da produção de farinha de mandioca com elevada carga poluente e tóxica, que pode contaminar cursos d'água e os solos, se não for corretamente descartada. Em contraponto, a produção de farinha é uma importante fonte de renda, sobretudo para pequenos agricultores familiares que, em geral, não têm recursos necessários para tratar esse efluente antes de descartá-lo. Além disso, essas pequenas comunidades produtoras não têm o devido conhecimento técnico sobre os danos ambientais do despejo dessa água residuária no ambiente sem qualquer tratamento preliminar. Ao identificar que se trata de um problema ambiental comum no agreste pernambucano foi instalada uma usina na cidade de Lajedo-PE para produzir etanol a partir da manipueira. Este trabalho teve como principal objetivo a otimização operacional da produção de biodiesel usando álcool de manipueira e óleo vegetal de algodão, também bastante produzido na região. O biodiesel foi produzido na usina de Caetés-PE gerenciada pelo Centro de Tecnologias Estratégicas do Nordeste - CETENE. O etanol passou por um processo de purificação que contou com destilação azeotrópica e desidratação por glicerol a fim de se obter álcool anidro. O biodiesel produzido se mostrou de excelente qualidade com teores de éster acima de $98 \%$.

\section{Use of manioc flour manufacturing residue for optimized biodiesel production}

\begin{abstract}
During the manufacture of cassava flour after the pressing process occurs the extraction of a liquid rich in hydrocyanic acid, venomous for animal nutrition, popularly known as manipueira. The manipueira is the residual water from the production of cassava flour with high polluting and toxic load, which can contaminate waterways and soils if not correctly discarded. In contrast, the production of flour is an important source of income, especially for small family farmers who generally do not have the resources to treat this effluent before disposal. In addition, these small producing communities do not have the necessary technical knowledge about the environmental damage of dumping this wastewater into the environment without any preliminary treatment. By identifying that this is a common environmental problem in the rough state of Pernambuco, a plant was installed in the city of Lajedo-PE to produce ethanol from the handling plant. The main objective of this work was the operational optimization of biodiesel production using alcohol from the handling plant and vegetable oil from cotton, also widely produced in the region. The biodiesel was produced in the Caetés-PE plant managed by the Northeast Strategic Technologies Center - CETENE. The ethano underwent a purification process that included azeotropic distillation and dehydration by glycerol in order to obtain anhydrous alcohol. The biodiesel produced was of excellent quality with ester contents above $98 \%$.
\end{abstract}

Keywords: Cassava; Manioc; Manipueira; Biodiesel; Operational optimization.

Érica Janaina de Moraes Dantas (iD) Universidade Federal de Pernambuco, Brasil http://lattes.cnpq.br/2969951711119223 http://orcid.org/0000-0002-0464-0342 ericaaadantas@gmail.com

Isabelle Cristine Prohmann Tschoeke (iD) Universidade Federal Rural de Pernambuco, Brasi http://lattes.cnpq.br/1308106432646901 http://orcid.org/0000-0002-0958-4386 isabelletschoeke@gmail.com

\section{Josivan Pedro da Silva (iD}

Universidade Federal de Pernambuco, Brasil http://lattes.cnpq.br/1251191721735872 http://orcid.org/0000-0003-3294-9352 josivan silva@hotmail.com

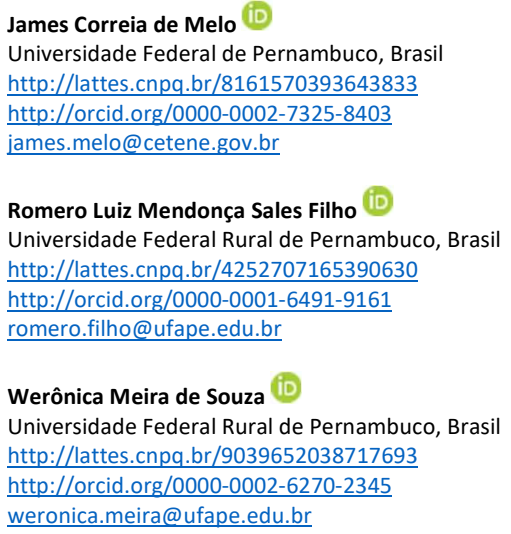

Werônica Meira de Souza

Universidade Federal Rural de Pernambuco, Brasil http://lattes.cnpq.br/9039652038717693 http://orcid.org/0000-0002-6270-2345

weronica.meira@ufape.edu.br

\author{
Marilene da Silva Lima (iD) \\ Universidade Federal Rural de Pernambuco, \\ Brasil \\ http://lattes.cnpq.br/8373599117775134 \\ http://orcid.org/0000-0001-8003-8962 \\ marilene.lima@ufape.edu.br
}

Thibério Pinho Costa Souza (iD)

Universidade Federal de Pernambuco, Brasil http://lattes.cnpq.br/4506927856419053 http://orcid.org/0000-0001-9452-948X

thiberio.souza@ufape.edu.br
Referencing this:

DANTAS, E. J. M.; TSCHOEKE, I. C. P.; SILVA, J. P.; MELO, J. C.; SALES FILHO, R. L. M.; SOUZA, W. M.; LIMA, M. S.; SOUZA, T. P. C.. Uso de resíduo da fabricação da farinha de mandioca para produção otimizada de biodiesel. Revista Ibero Americana de Ciências Ambientais, v.12, n.2, p.419-427, 2021. DOI: http://doi.org/10.6008/CBPC2179-6858.2021.002.0036 


\section{INTRODUÇÃO}

A produção de mandioca no município de Lajedo, localizado no agreste pernambucano, data a partir da segunda metade do século 20 , as primeiras casas de farinha foram construídas para suprir a alimentação das pessoas que residiam na região. As casas de farinha evoluíram do tipo tradicional, ou seja, partiram da produção completamente manual até o tipo modernizado que possui prensa hidráulica e monotriturador (BARROS JÚNIOR, 2015).

A manufatura de farinha de mandioca é de extrema importância econômica em Lajedo e região pois emprega homens e mulheres de baixa renda e baixa escolaridade e dão oportunidade de sobrevivência, mesmo diante de baixos salários, a essas pessoas. Mesmo após o desenvolvimento tecnológico no processamento de tubérculos, a fabricação de farinha permanece rudimentar na região. Não há produção mecanizada, utilização de fertilizantes, controle fitossanitário nem tratamento dos efluentes gerados (BARROS JÚNIOR et al., 2016).

Durante o processamento da mandioca é inerente a produção de resíduos sólidos e efluentes proporcional à quantidade de raízes, gerando cerca de $18 \%$ de cascas; $30 \%$ de manipueira e $24 \%$ de aglomerados e perdas com a evaporação. A principal preocupação ambiental nos resíduos gerados é com a manipueira, pois a mesma tem elevado potencial poluente, 25 vezes maior que o esgoto. Ademais, observase elevada toxidade da água residual, devido a um glicosídeo (linamarina) que quando hidrolisado, convertese em glicose, acetona e ácido cianídrico (TSCHOEKE et al., 2017)

As raízes da mandioca, depois de utilizadas para produção de farinha, fécula (polvilho doce ou azedo) e tapioca, gera alguns subprodutos, como resíduos sólidos e efluentes líquidos, conhecido como manipueira (extrato líquido das raízes da mandioca). A manipueira foi por muito tempo descartada pela toxicidade, mas a composição química da manipueira mostra um bom potencial para ser usada como fertilizante, devido a sua riqueza em potássio, nitrogênio, magnésio, fósforo, cálcio e enxofre, além de ferro e micronutrientes (SILVA et al., 2018).

Dentre os principais reúsos do efluente produzido no processamento da mandioca destaca-se: fertilizantes de solo, como pesticida pode ser usado no combate a pragas, insetos, formigas, na cultura de hortaliças, na produção de vinagre e de tijolos (SEBRAE, 2014). Propondo um fim mais nobre, esse trabalho sugere reaproveitar a manipueira na produção de biodiesel.

O estado de Pernambuco possui uma usina piloto designada a produção de etanol oriundo do efluente hídrico das casas de farinha. A usina, que recebeu investimento de $\mathrm{R} \$ 800 \mathrm{mil}$, é o primeiro projeto do Programa Vera (Valorização Energética de Resíduos da Agropecuária e Agroindústria), que tem como objetivo o desenvolvimento tecnológico e a implantação de unidades de aproveitamento de resíduos para produção de energia renovável, especialmente em economias familiares. O principal objetivo da usina é a produção de bioetanol que é destinado a instituições de pesquisa no estado para ser usado, por exemplo, como reagente alcoólico na produção de biodiesel que em seguida passará por certificação exigida pela Agência Nacional de Petróleo, Gás Natural e Biocombustíveis (ANP). O biodiesel produzido será testado em 
motores diesel visando sua adequação para futura utilização no abastecimento dos veículos da prefeitura de Lajedo e possivelmente do governo do estado de Pernambuco. O biodiesel pode ser usado nos motores sem qualquer alteração no sistema do motor, pois suas características de combustão são semelhantes às do diesel convencional (NOOR et al., 2018).

A usina produz também biogás, o qual é utilizado para suprir suas próprias necessidades energéticas, e biofertilizante que é empregado na agroindústria da mandioca e no campo experimental da unidade. A usina experimental é um sistema integrado formado por biodigestores, uma central de utilidades (cogeração) e uma microdestilaria de álcool de manipueira. A usina cria um sistema de alimentação recíproca no qual os rejeitos da microdestilaria (vinhaça) e a matéria prima excedente (manipueira) constituirão a massa biodegradável para os digestores, enquanto que o biogás produzido alimentará a central de utilidades que fornecerá energia térmica e elétrica para a microdestilaria.

A usina experimental de Lajedo produz anualmente 70.000 litros de bioetanol. Atualmente, a unidade tem capacidade instalada para processar 4,8 milhões de litros de manipueira por ano, o que corresponde a $20 \%$ da produção de farinha do município. Outra vertente deste trabalho está na segunda etapa do processo, a usina piloto de biodiesel localizada na cidade de Caetés/PE. Com a produção de biodiesel fazendo uso da rota etílica a partir do álcool de manipueira proveniente da usina de Lajedo, o ciclo energético é fechado de forma ecologicamente correta. Preocupações com o meio ambiente têm levado a necessidade de estudos para o uso de combustíveis ecologicamente corretos (DEMIRBAS, 2008).

A diversidade de matérias primas, de processos e de usos é uma grande vantagem, contudo, levanos à responsabilidade de analisar adequadamente os parâmetros que podem variar significativamente, dependendo da escolha feita, tais como os custos totais envolvidos em sua produção, as emissões no ciclo de vida, as possibilidades de geração de emprego, as disponibilidades de área e mão de obra adequada. 0 rendimento e otimização no processo de produção de biodiesel depende de fatores operacionais como o reagente alcoólico empregado, a razão molar álcool/óleo, a concentração e o tipo de catalisador, a qualidade da matéria prima, a temperatura, pressão e tempo de reação além da agitação do meio reacional e geometria dos equipamentos utilizados no processo (BIRLA et al., 2012; CETINKAYA et al., 2004; DORADO et al., 2004).

A reação de transesterificação é chave importante para produzir o combustível mais limpo e ambientalmente seguro a partir de óleos vegetais (MEHER et al., 2006). Um dos fatores importantes para o estudo das reações de biodiesel está no conhecimento dos seus parâmetros cinéticos (MELO et al., 2007). A reação de transesterificação ocorre quando um óleo de origem vegetal, ou gordura animal, entra em contato com um álcool (YEE et al., 2010; BARBOSA et al., 2010). O produto desta reação é uma mistura de ésteres (biodiesel) e glicerol. Este trabalho teve o objetivo de otimizar o processo de produção de biodiesel a partir da reação de transesterificação do óleo vegetal de algodão com álcool de manipueira e visou estudar, do ponto de vista industrial, um processo produtivo integrado de duas plantas pilotos (etanol e biodiesel), unindo assim a cadeia energética da região no agreste do estado. 


\section{MATERIAIS E MÉTODOS}

O efluente usado no processo foi oriundo das casas de farinha da região de Lajedo/PE. A mandioca foi processada pelos agricultores que, em vez de descartarem o resíduo, a manipueira foi levada para a usina piloto instalada na cidade. O efluente passou por um processo de hidrólise onde o amido contido na manipueira foi convertido em açucares redutores. O processo consiste em uma etapa ácida e uma etapa enzimática para a conversão do amido. Na hidrólise enzimática foi utilizado um complexo de enzimas alfaamilase que fazem a maior parte da transformação. Em seguida, o produto foi direcionado para a etapa fermentativa, onde foi inserido o fermento (levedura) a fim de se converter os açúcares em álcool. Por fim, o líquido fermentado foi enviado para a etapa de destilação onde é separado o etanol. A Figura 1 mostra os equipamentos para o processo fermentativo (a) e para o processo de destilação (b).

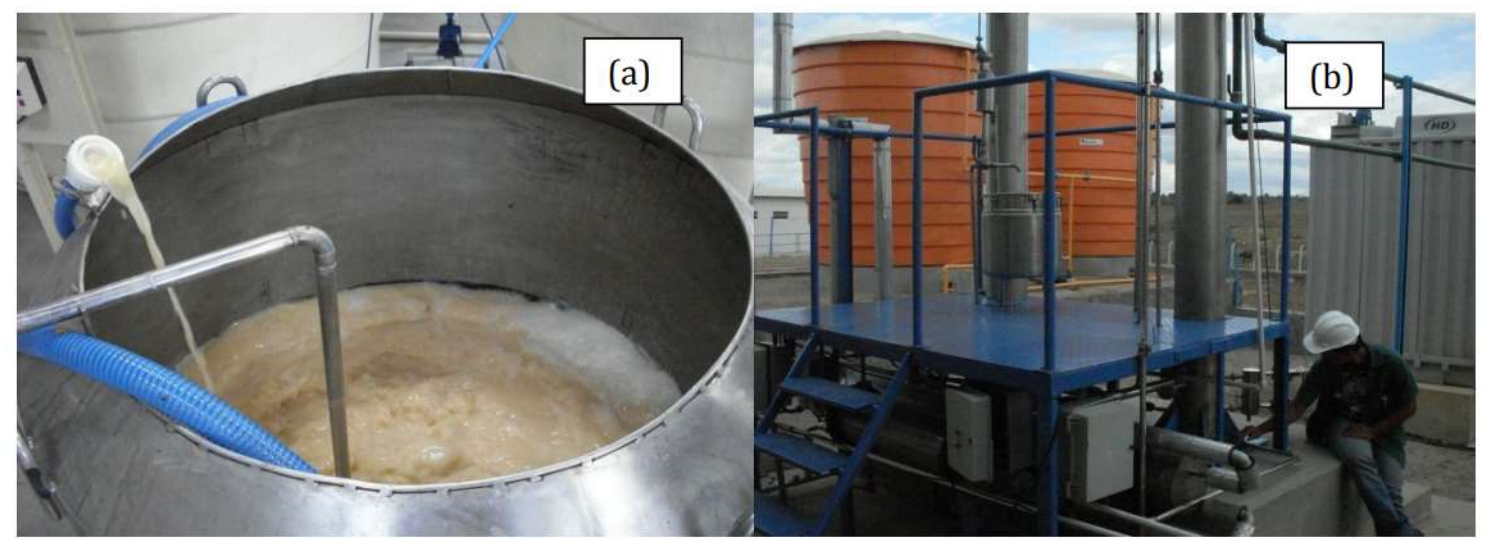

Figura 1: Equipamentos industriais da usina de Lajedo (a) fermentador e (b) colunas de destilação.

O álcool de manipueira da usina de Lajedo foi direcionado para a usina piloto de Caetés/PE servindo de reagente alcoólico no processo de reação com óleo vegetal para a produção de biodiesel, utilizando os equipamentos das instalações industriais mostrado na Figura 2.

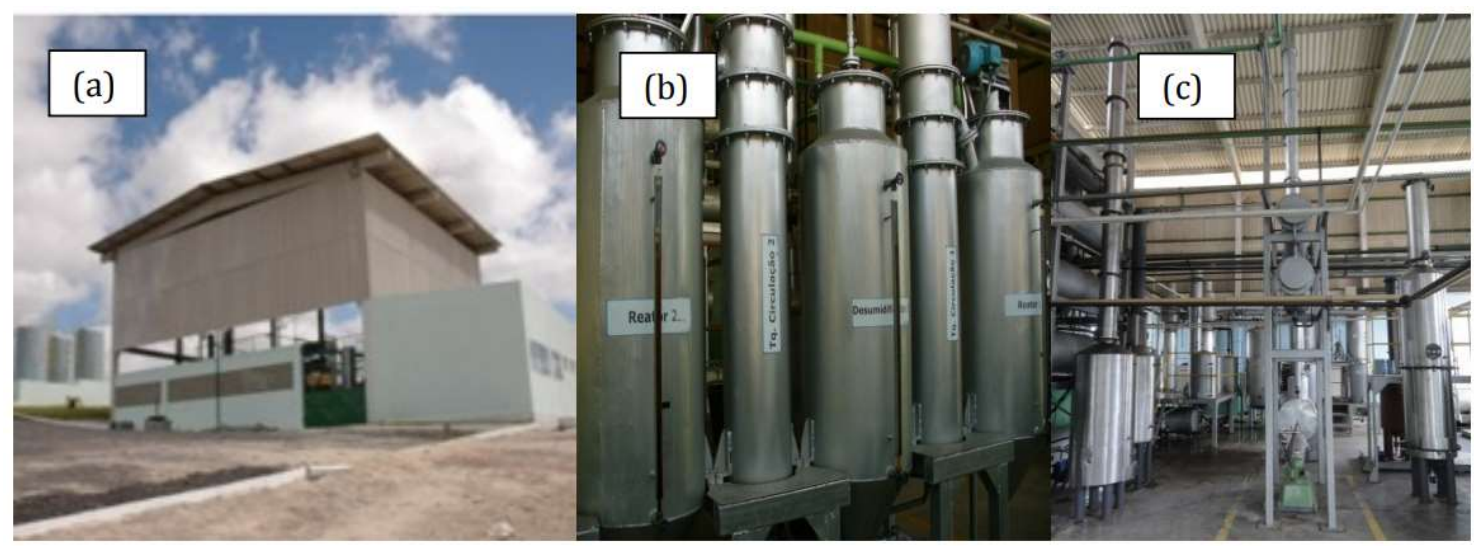

Figura 2: (a) Usina Piloto de Biodiesel de Caetés/PE e equipamentos industriais (b) reatores de biodiesel e (c) colunas de destilação.

Inicialmente o etanol hidratado oriundo da usina de Lajedo/PE foi submetido a destilação extrativa em coluna com altura de 4 metros dividida em 30 estágios com recheios de anéis de 'raschig' (antes de ser direcionado para a etapa de produção de biodiesel a fim de se remover a água contida evitando problemas de reações paralelas como a saponificação). A coluna de extração opera de forma a aproveitar a própria 
glicerina gerada na usina como solvente. A glicerina possui uma afinidade pela água, extraindo-a por arraste através da coluna. $\mathrm{O}$ etanol, mais leve no processo, é retirado no topo da coluna.

Os ésteres etílicos de ácidos graxos foram obtidos em reação de transesterificação com catálise básica. O catalisador etóxido de sódio foi preparado na reação do etanol com hidróxido de sódio. Em seguida, o etanol com o catalisador foi direcionado para os reatores onde recebeu o óleo vegetal de algodão para dar início da reação. Após um ciclo de uma batelada, o produto reacional foi direcionado para um sistema de decantação onde são separados os ésteres (biodiesel) e a glicerina. Separada as fazes, o biodiesel foi submetido ao processo de neutralização, sob agitação por 10 minutos e em seguida a água e sal foram separados do biodiesel por centrifugação.

Posteriormente o biodiesel foi lavado novamente apenas com água para retirar impurezas ainda presentes. Após o processo de lavagem e centrifugação, o biodiesel foi submetido à secagem em desumidificador por sistema de 'flasheamento' em uma temperatura de $90^{\circ} \mathrm{C}$ sob pressão reduzida de 25 pol de Hg. Um planejamento de experimentos foi realizado considerando três fatores, com o objetivo de otimizar o processo obtendo o máximo de informação útil com relação às melhores conversões. As seguintes variáveis de operação foram analisadas: relação molar etanol/óleo $(6 / 1 ; 7,5 / 1 ; 9 / 1)$; quantidade de base $\mathrm{NaOH}(0,5 \%$; 0,75\%; 1\%), em relação a massa de óleo, para formação do catalisador etóxido de sódio e temperatura de reação $\left(40^{\circ} \mathrm{C} ; 50^{\circ} \mathrm{C} ; 60^{\circ} \mathrm{C}\right)$. Os experimentos foram realizados em sequência definida por sorteio e o desempenho da reação foi medido avaliando-se a conversão em éster por cromatografia gasosa, seguindo o método EN 14103.

\section{RESULTADOS E DISCUSSÃO}

O álcool de manipueira obtido na usina de Lajedo apresentou teor alcoólico de 85,6\% em volume. Este álcool foi direcionado para a usina piloto de Caetés/PE para a produção do biodiesel. Antes da produção do biodiesel, o álcool de manipueira foi submetido a destilação extrativa em coluna com altura de 4 metros dividida em 30 estágios com recheios de anéis de 'raschig'. Em estudo preliminar de simulação foi considerado uma razão entre glicerol e etanol de 10/1 afim de concentrar o álcool passando de $85 \%$ para $98 \%$. A base da coluna foi mantida a $120^{\circ} \mathrm{C}$ enquanto o topo foi registrado temperatura de $78,5^{\circ} \mathrm{C}$. Na planta piloto foi obtido etanol em concentração de $97,3 \%$.

Para melhorar a concentração do etanol de manipueira, o mesmo foi misturado com álcool anidro $(99,9 \%)$ obtido comercialmente de destilarias de álcool de cana de açúcar. Na mistura foi obtido etanol a $99,1 \%$, sendo este utilizado para produzir o biodiesel. A glicerina purificada na usina piloto de biodiesel de Caetés foi utilizada como solvente por possuir uma afinidade pela água, extraindo-a por arraste através da coluna, enquanto o etanol, mais leve no processo, foi retirado no topo da coluna. No processo de transesterificação foi realizado um estudo variando-se 3 fatores, a temperatura da reação, relação etanol/óleo e concentração de base $\mathrm{NaOH}$. As variáveis independentes foram estipuladas entre $40^{\circ} \mathrm{C}$ e $60^{\circ} \mathrm{C}$ no caso da temperatura, 6/1 e 9/1 para a relação molar etanol/óleo e 0,5\% e 1\% para a base do catalisador, sendo 3 níveis para cada, conforme mostra a Tabela 1. Para cada ensaio foi registrado o teor de éster obtido 
em termos da conversão mostrado na Tabela 2.

Tabela 1: Planejamento experimental $33(*)$.

\begin{tabular}{l|l|l|l}
\hline Nível & -1 & 0 & 1 \\
\hline Temperatura $\left({ }^{\circ} \mathrm{C}\right)$ & 40 & 50 & 60 \\
\hline Relação molar etanol/óleo & $6 / 1$ & $7,5 / 1$ & $9 / 1$ \\
\hline $\mathrm{NaOH}(\%)$ & 0,5 & 0,75 & 1 \\
\hline
\end{tabular}

* Variáveis mantidas fixas: quantidade de óleo de algodão; Tempo de reação de uma hora e velocidade de agitação de $300 \mathrm{rpm}$.

Tabela 2: Efeito da temperatura de reação (T), da relação etanol/óleo (EO) e da concentração de catalisador (C) na reação de transesterificação em termos da conversão $(X)$

\begin{tabular}{l|l|l|l|l}
\hline Experimento & Temperatura & Relação Molar EtOH/Óleo & NaOH & Conversão em Éster \% \\
\hline 1 & -1 & -1 & -1 & 89,4 \\
2 & -1 & -1 & 0 & 94,1 \\
3 & -1 & -1 & +1 & 97,0 \\
4 & -1 & 0 & -1 & 95,2 \\
5 & -1 & 0 & 0 & 97,3 \\
6 & -1 & 0 & +1 & 98,7 \\
7 & -1 & +1 & -1 & 92,0 \\
8 & -1 & +1 & 0 & 98,9 \\
9 & -1 & -1 & +1 & 98,2 \\
10 & 0 & -1 & -1 & 92,0 \\
11 & 0 & -1 & 0 & 96,0 \\
12 & 0 & 0 & +1 & 98,1 \\
13 & 0 & 0 & -1 & 96,2 \\
14 & 0 & 0 & 0 & 97,3 \\
15 & 0 & +1 & +1 & 98,6 \\
16 & 0 & +1 & -1 & 98,4 \\
17 & 0 & +1 & 0 & 98,6 \\
18 & 0 & -1 & +1 & 99,0 \\
19 & +1 & -1 & -1 & 93,9 \\
20 & +1 & -1 & 0 & 96,0 \\
21 & +1 & 0 & +1 & 97,1 \\
22 & +1 & 0 & -1 & 97,5 \\
23 & +1 & 0 & 0 & 98,1 \\
24 & +1 & +1 & +1 & 94,0 \\
26 & +1 & +1 & -1 & 99,1 \\
27 & +1 & +1 & 0 & 97,0 \\
\hline & +1 & & +1 & 96,0 \\
\hline
\end{tabular}

Para a realização dos experimentos foi efetuado um sorteio de modo que a ordem de realização foi aleatória. Um total de oito medidas foram repetidas para a obtenção de uma estimativa do erro aleatório, com o intuito de estabelecer um critério quantitativo para avaliação se o modelo escolhido foi uma boa representação das observações. Os experimentos em duplicata foram realizados após sorteio. Os coeficientes do modelo e seus erros padrões foram calculados utilizando a técnica de ajuste por mínimos quadrados. Para a conversão, o emprego do modelo quadrático resultou na Equação 1.

$$
\begin{gathered}
X=98,29+0,44 \cdot T+1,31 \cdot(E O)+1,28 \cdot C-1,05 \cdot T^{2}-0,83 \cdot(E O)^{2}-0,90 \cdot C^{2}-0,29 . T .(E O)-1,73 \cdot T \cdot C- \\
1,10 .(E O) \cdot C \quad(1) \\
\pm 0,34 \quad \pm 0,16 \pm 0,16 \quad \pm 0,16 \quad \pm 0,27 \quad \pm 0,27 \quad \pm 0,27 \quad \pm 0,19 \quad \pm 0,19 \quad \pm 0,19
\end{gathered}
$$

A análise de variância para o ajuste é mostrada na Tabela 3. $O$ valor da razão MQR/MQr foi superior ao valor de $F_{9,25}$, indicando que a regressão foi satisfatória. Observa-se na Figura 3 que a distribuição dos resíduos é aleatória no intervalo estudado e em torno do valor zero. 
Tabela 3: Análise da variância para o ajuste do modelo quadrático aos valores de conversão em éster.

\begin{tabular}{l|l|l|l}
\hline Fonte de variação & Soma quadrádica & $\mathbf{N}^{\circ}$ de g. I. & Média quadrática \\
\hline Regressão & 130,69 & 9 & 14,52 \\
Resíduos & 28,59 & 25 & 1,14 \\
F. ajuste & 25,07 & 17 & 1,47 \\
Erro puro & 3,52 & 8 & 0,44 \\
\hline Total & 159,28 & 34 & \\
\hline$\%$ de variação explicada: & 0,82 & \\
\% máxima de variação explicável: & & 0,98 & \\
\hline $\mathrm{MQ}_{\mathrm{R}} / \mathrm{MQ}_{\mathrm{r}}=12,70$ & & $\mathrm{~F}_{9,25}=2,28$ (no nível de $\left.95 \%\right)$ \\
\hline
\end{tabular}

A Figura 4 mostra o gráfico de paridade da conversão calculada pelo modelo versus a conversão medida experimentalmente. Pode-se observar que a dispersão dos pontos em torno da reta de 45 graus é pequena no modelo quadrático estudado, confirmando que este é adequado.

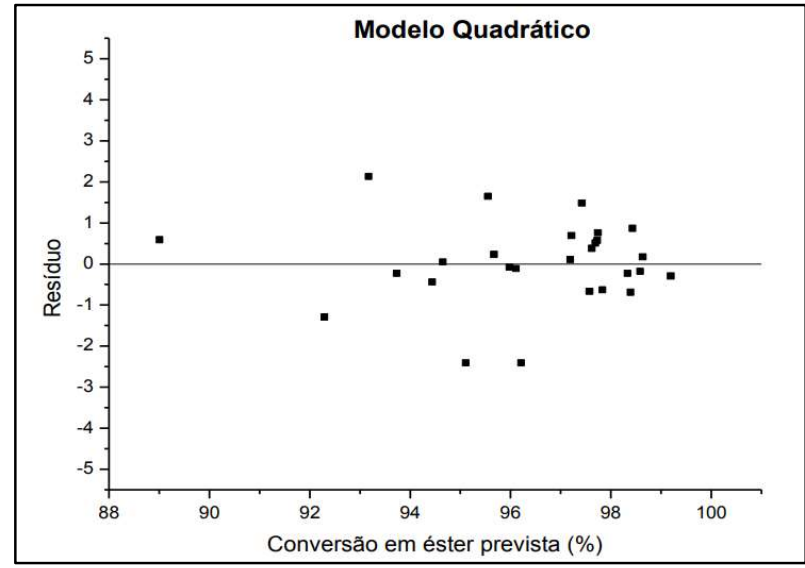

Figura 3: Resíduos dos valores de conversão em éster para o modelo quadrático estudado.

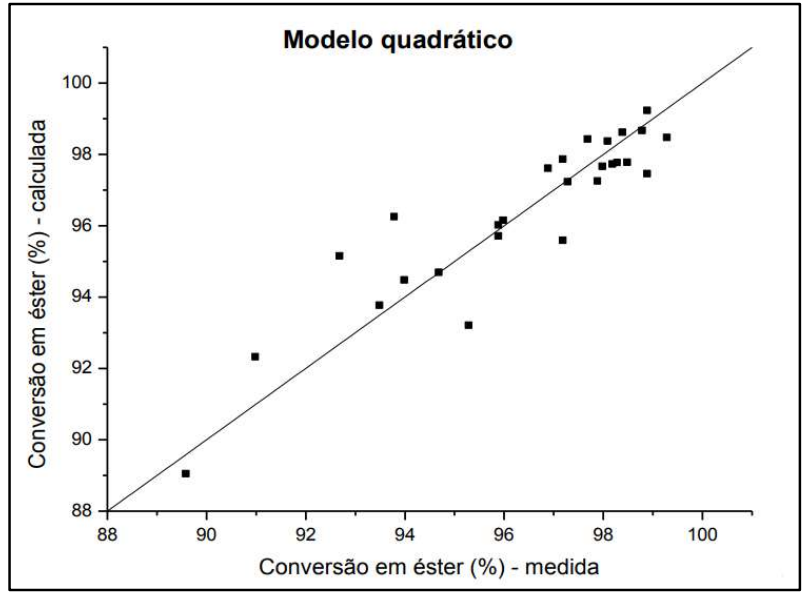

Figura 4: Conversão calculada versus conversão medida para o modelo quadrático.

Os melhores resultados foram obtidos com o aumento da quantidade de catalisador e de etanol. No intervalo estudado a condição ótima de reação é obtida na temperatura próxima de $40^{\circ} \mathrm{C}$, na relação etanol/óleo próxima 7,5/1 e com 1\% de concentração de catalisador, com teor de éster acima de $98 \%$, indicando que o etanol obtido da manipueira pode ser utilizado na produção de biodiesel. Outros parâmetros foram avaliados e o biodiesel ficou dentro da especificação exigida na Resolução ANP no 14, de 11.5.2012, conforme apresentado na Tabela 4.

Tabela 4: Propriedades do biodiesel de algodão produzido com álcool de manipueira na usina piloto do CETENE em Caetés/PE, na temperatura de $40^{\circ} \mathrm{C}$; relação etanol/óleo 7,5/1; concentração de base $\mathrm{NaOH}$ para o catalisador de $1 \%$; velocidade de agitação de $300 \mathrm{rpm}$ e tempo de reação de $1 \mathrm{~h}$.

\begin{tabular}{lllll}
\hline Característica & Método & Unidade & Valor & Resolução ANP no 14/2012 \\
\hline Massa específica a $20^{\circ} \mathrm{C}$ & ASTM D 4052 & $\mathrm{kg} / \mathrm{m}^{3}$ & 880,1 & 850 a 900 \\
Viscosidade cinemática a $40^{\circ} \mathrm{C}$ & ASTM D 445 & $\mathrm{mm}^{2} / \mathrm{s}$ & 4,3 & 3,0 a 6,0 \\
Teor de água & ASTM D 6304 & $\mathrm{mg} / \mathrm{kg}$ & 190 & $\leq 200$ \\
Ponto de fulgor & ASTM D 93 & ${ }^{\circ} \mathrm{C}$ & 158 & $\geq 100$ \\
Teor de éster & EN 14103 & $\%$ massa & 98,6 & $\geq 96,5$ \\
Índice de acidez & ASTM D 664 & $\mathrm{mg} \mathrm{KOH} / \mathrm{g}$ & 0,55 & $\leq 0,80$ \\
\hline
\end{tabular}

De posse dos resultados experimentais, foi realizado uma simulação do processo para as temperaturas de $30^{\circ} \mathrm{C}, 40^{\circ} \mathrm{C}, 50^{\circ}$ e $60^{\circ} \mathrm{C}$. Foi utilizado com ferramenta o software Aspen puls ${ }^{\circledR}$ e foi utilizado o pacote termodinâmico UNIFAC. Foi utilizado um tempo total de processo de 60 minutos. Os resultados da simulação podem ser vistos na Figura 5 abaixo. 


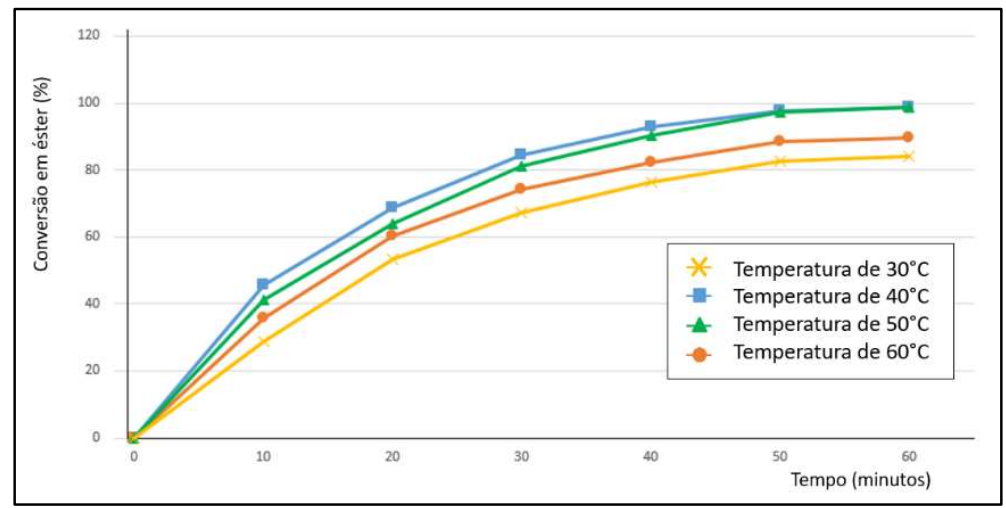

Figura 5: Conversão em éster processo utilizando álcool de manipueira para as temperaturas de $30^{\circ} \mathrm{C}, 40^{\circ} \mathrm{C}, 50^{\circ} \mathrm{C}$ e $60^{\circ} \mathrm{C}$.

Pode-se verificar que a melhor temperatura para o processo foi a de $40^{\circ} \mathrm{C}$ conforme mostrado nos resultados experimentais. $\mathrm{O}$ processo com temperatura de $50^{\circ} \mathrm{C}$ foi bastante satisfatório. Já a aplicação para temperaturas de $30^{\circ} \mathrm{C}$ e $60^{\circ} \mathrm{C}$ não é vantajoso, pois nessas faixas a reação fica mais lenta $\left(30^{\circ} \mathrm{C}\right)$ ou se perde muito álcool da fase líquida por evaporação $\left(60^{\circ} \mathrm{C}\right)$ diminuindo a relação molar óleo/álcool.

\section{CONCLUSÕES}

O estudo mostrado neste trabalho avalia a otimização na produção de biodiesel considerando a integração de duas plantas piloto no estado de Pernambuco. Os resultados foram bastante satisfatórios mostrando a viabilidade da utilização do álcool obtido de manipueira, resíduo de casas de farinha. $O$ etanol obtido com concentração de $85 \%$ pode ser destilado até obtenção da mistura azeotrópica em coluna de destilação antecedendo a desidratação por extração líquido/líquido. O glicerol mostrou ser eficiente nesse tipo de desidratação do etanol. Este processo requer um melhor planejamento visando a otimização para obter um álcool com maior grau de pureza acima dos $97,3 \%$ obtido na planta piloto.

Em relação a otimização da produção de biodiesel a partir da transesterificação do óleo vegetal de algodão com etanol proveniente de manipueira, o modelo quadrático analisado mostrou ser satisfatório para estimar a conversão em termos da temperatura, relação etanol/óleo e concentração de catalisador, no intervalo estudado. Condição ótima de reação foi obtida na temperatura de $40^{\circ} \mathrm{C}$, na relação etanol/óleo 7,5/1 e com $1 \%$ de concentração de catalisador. O biodiesel obtido apresentou teor de éster acima da exigência da ANP além de ficar adequado em relação a outros parâmetros de qualidade.

Novos experimentos serão realizados com o intuito de melhorar a eficiência energética para o uso de álcool de manipueira na produção de biodiesel e o biocombustível será testado em motores diesel visando sua adequação para futura utilização no abastecimento de veículos de prefeitura e possivelmente do governo do estado de Pernambuco. De forma geral no processo produtivo integrado das duas plantas pilotos de etanol e biodiesel, os resultados da otimização se mostraram eficazes, indicando que o etanol oriundo do efluente da manipueira possa ser um excelente álcool para a produção de biodiesel. 


\section{REFERÊNCIAS}

BARBOSA, D. C.; SERRA, T. M.; MENEGHETTI, S. M. P.; MENEGHETTI, M. R.. Biodiesel production by ethanolysis of mixed castor and soybean oils. Fuel, v.89, n.12, p.3791-3794, 2010. DOI: http://doi.org/10.1016/j.fuel.2010.07.016

BARROS JÚNIOR, A. P.. Impactos ambientais da vulnerabilidade dos trabalhadores nas casas de farinha no agreste pernambucano. Dissertação de mestrado (Mestrado em Desenvolvimento e Meio Ambiente) - Universidade Federal de Pernambuco, Recife, 2015.

BARROS JÚNIOR, A. P.; SOUZA, W. M.; ARAÚJO, M. S. B.. Produção de farinha de mandioca no agreste pernambucano. Equador, v.5, n.5, p.216-238, 2016.

BIRLA, A.; SINGH, B.; UPADHYAY, S. N.; SHARMA, Y. C.. Kinetics studies of synthesis of biodiesel from waste frying oil using a heterogeneous catalyst derived from snail shell. Bioresource Technology, v.106, p.95-100, 2012. DOI: http://doi.org/10.1016/j.biortech.2011.11.065

CETINKAYA, M.; KARAOSMANOǦLU, F.. Optimization of Base-Catalyzed Transesterification Reaction of Used Cooking Oil. Energy \& Fuels, v.18, n.6, p.1888-1895, 2004. DOI: http://doi.org/10.1021/ef049891c

DEMIRBAS, A.. Comparison of transesterification methods for production of biodiesel from vegetable oils and fats. Energy Conversion and Management, v.49, n.1, p.125-130, 2008. DOI: http://doi.org/10.1016/i.enconman.2007.05.002

DORADO, M. P.; BALLESTEROS, E.; LÓPEZ, F. J.; MITTELBACH, M.. Optimization of alkali-catalyzed transesterification of Brassica Carinata oil for biodiesel production. Energy \& Fuels, v.18, n.1, p.77-83, 2004. DOI: http://doi.org/10.1021/ef0340110
MEHER, L.; VIDYASAGAR, D.; NAIK, S.. Technical aspects of biodiesel production by transesterification: a review.

Renewable and Sustainable Energy Reviews, v.10, n.3, p.248-268, 2006. DOI:

http://doi.org/10.1016/j.rser.2004.09.002

MELO, J. C.; PACHECO, J. G. A.; STRAGEVITCH, L.; BARBOSA, F. L. P.; JUCÁ, J. F. T.; NEVES, A. M.. Cinética da reação de transesterificação do óleo de algodão para produção de biodiesel. In: CONGRESSO DA REDE BRASILEIRA DE TECNOLOGIA DE BIODIESEL, 2. Anais. Brasília: ABIPTI, 2007.

NOOR, C. W. M.; NOOR, M. M.; MAMAT, R.. Biodiesel as alternative fuel for marine diesel engine applications: $A$ review. Renewable and Sustainable Energy Reviews, v.94, p.127-142, 2018. DOI: http://doi.org/10.1016/j.rser.2018.05.031

SEBRAE. Como usar corretamente a manipueira. Brasília: SEBRAE, 2014.

SILVA, C.; SOUZA, T.; OLIVEIRA, E.. Produtividade do milho sob uso de manipueira. In: CONGRESSO LATINO AMERICANO DE AGROECOLOGIA, 6; CONGRESSO BRASILEIRO DE AGROECOLOGIA, 10; E SEMINÁRIO DE AGROECOLOGIA DO DF E ENTORNO, 5. Anais. Brasília, 2018.

TSCHOEKE, I. C. P.; SILVA, L. F.; SALES, A. F. M.; SOUZA; T. P. $C$.. Análise da carga orgânica da manipueira em casas de farinha. Revista Brasileira de Agrotecnologia, v.7, n.2, p.228-232, 2017.

YEE, K. F.; KANSEDO, J.; LEE, K. T.. Biodiesel production from palm oil via heterogeneous transesterification: optimization study. Chemical Engineering Communications, v.197, n.12, p.1597-1611, 2010. DOI:

http://doi.org/10.1080/00986445.2010.500156

A CBPC - Companhia Brasileira de Produção Científica (CNPJ: 11.221.422/0001-03) detém os direitos materiais desta publicação. Os direitos referem-se à publicação do trabalho em qualquer parte do mundo, incluindo os direitos às renovações, expansões e disseminações da contribuição, bem como outros direitos subsidiários. Todos os trabalhos publicados eletronicamente poderão posteriormente ser publicados em coletâneas impressas sob coordenação da Sustenere Publishing, da Companhia Brasileira de Produção Científica e seus parceiros autorizados. Os (as) autores (as) preservam os direitos autorais, mas não têm permissão para a publicação da contribuição em outro meio, impresso ou digital, em português ou em tradução. 